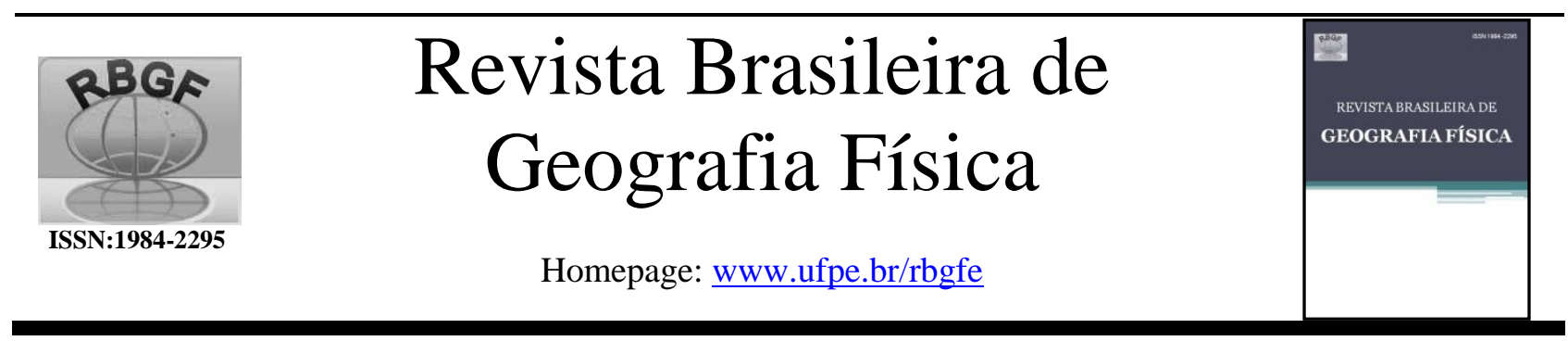

\title{
Análise da balneabilidade das águas estuarinas da Reserva de Desenvolvimento Sustentável Estadual Ponta do Tubarão - Rio Grande do Norte, Brasil
}

\author{
Joilson Marques Ferreira Filhoㄹ, Francisco Marlon Carneiro Feijón ${ }^{2}$, Rodrigo Guimarães de Carvalho ${ }^{3}$, \\ Genevile Carife Bergamo ${ }^{4}$, Palloma Vitória Carlos de Oliveira ${ }^{5}$, Tayná Moura Matos ${ }^{6}$, Caio Sérgio \\ Santos $^{7}$
}

\begin{abstract}
${ }^{1}$ Mestre em Ambiente, Tecnologia e Sociedade pela Universidade Federal Rural do Semi-Árido (PPGATS/UFERSA), Mossoró, RN, Brasil, jmarquesff@gmail.com (autor correspondente). ${ }^{2}$ Professor na Universidade Federal Rural do Semi-Árido (UFERSA), Mossoró, RN, Brasil, Laboratório de Microbiologia Veterinária, marlon@ufersa.edu.br. ${ }^{3}$ Professor na Universidade do Estado do Rio Grande do Norte (UERN), Mossoró, RN, Brasil, Laboratório de Estudos Costeiros e Áreas Protegidas - LECAP, rodrigo.ufc @ gmail.com. ${ }^{4}$ Professor na Universidade Federal Rural do SemiÁrido (UFERSA), Mossoró, RN, Brasil, Departamento de Ciências Agronômicas e Florestais, gcbergamo@ufersa.edu.br. ${ }^{5}$ Graduanda em Zootecnia na Universidade Federal Rural do Semi-Árido (UFERSA), Mossoró, RN, Brasil, pallomavictoria@ hotmail.com.br. ${ }^{6}$ Graduanda em Medicina Veterinária na Universidade Federal Rural do Semi-Árido (UFERSA), Mossoró, RN, Brasil, tattymouram @ gmail.com. ${ }^{7}$ Técnico Laboratório de Microbiologia Veterinária na Universidade Federal Rural do Semi-Árido (UFERSA), Mossoró, RN, Brasil, caio.srg@gmail.com.
\end{abstract}

Artigo recebido em 15/11/2017 e aceito em 16/06/2018

\section{R E S U M O}

A inexistência de saneamento básico possibilita que esgotos domésticos sejam lançados diretamente no estuário possibilitando o carreamento de variedades de micro-organismos patogênicos que põem em risco a saúde dos moradores. Objetivou-se então, conhecer os parâmetros microbiológicos, físico-químicos e os impactos ambientais do lançamento de efluentes domésticos e da disposição inadequada de resíduos sólidos urbanos no estuário da Reserva de Desenvolvimento Sustentável Estadual Ponta do Tubarão (RDSEPT). As coletas de 50 amostras de água foram realizadas nas comunidades de Chico Martins, Barreiras, Diogo Lopes e Sertãozinho em cinco pontos georreferenciados distintos. Os parâmetros microbiológicos foram mensurados através da técnica NMP para coliformes totais, coliformes termotolerantes, Escherichia coli e Enterococcus sp. Os parâmetros físico-químicos mensurados foram pH, salinidade através de um medidor multiparâmetro com GPS (Modelo HI 9828) e os impactos ambientais negativos por meio de check-list e registros fotográficos. Quanto aos coliformes totais e termotolerantes, foram encontrados valores dentro dos limites estabelecidos na legislação em 90\% das amostras, e 100\% das amostras de Escherichia coli e Enterococcus sp. foram consideradas próprias na categoria excelente. Por outro lado, por meio do check-list, foram georreferenciados 205 pontos de lançamento de efluentes domésticos e 7 áreas de disposição inadequada de resíduos sólidos urbanos em área de estuário, esses dados classificam que classifica a água do estuário como inapropriada para o banho. Concluiuse que as águas da orla estuarina da RDSEPT apresentam os índices físico-químicos de acordo com os padrões estabelecidos e estão contaminadas com bactérias de origem fecal, com concentrações inferiores aos limites permitidos. Palavras-chave: estuário, qualidade da água, monitoramento ambiental.

\section{Analysis of the balneability of the estuarine waters of the state sustainable development reserve Ponta do Tubarão - Rio Grande do Norte State, Brazil}

\section{A B S T R A C T}

The lack of basic sanitation makes it possible for domestic sewage to be discharged directly into the estuary, making it possible to carry varieties of pathogenic microorganisms that endanger the health of the residents. The objective was to know the microbiological, physical-chemical and environmental impacts of the discharge of domestic effluents and the inadequate disposal of urban solid waste in the estuary of the Ponta do Tubarão State Sustainable Development Reserve (RDSEPT). The samples of 50 water samples were taken in the communities of Chico Martins, Barreiras, Diogo Lopes 
and Sertãozinho in five different georeferenced points. Microbiological parameters were measured using the NMP technique for total coliforms, thermotolerant coliforms, Escherichia coli and Enterococcus sp. The physical-chemical parameters measured were $\mathrm{pH}$, salinity through a multi-parameter GPS meter (Model HI 9828) and negative environmental impacts through check-list and photographic records. As for total and thermotolerant coliforms, values within the limits established in the legislation were found in $90 \%$ of the samples, and $100 \%$ of the Escherichia coli and Enterococcus sp. were considered proper in the excellent category. On the other hand, through the checklist, 205 points of domestic effluent discharge and 7 areas of inadequate disposal of urban solid waste in an estuary area were georeferenced, these data classify the estuarine water as inappropriate for bathing. It was concluded that the estuarine waters of the RDSEPT present the physico-chemical indices according to established standards and are contaminated with fecal bacteria, with concentrations below the limits allowed

Keywords: estuary, water quality, environmental monitoring.

\section{Introdução}

A água é um recurso essencial para a existência de todos os organismos vivos, mas essa fonte de riqueza natural está em risco devido ao crescimento populacional com o consequente aumento da demanda da mesma para diferentes usos (Carr et al., 2010).

A qualidade das águas costeiras brasileiras é bastante influenciada pelas condições de saneamento básico existentes nas cidades litorâneas. Muitas cidades brasileiras estão localizadas à beira-mar e, na maioria dos casos, não possuem infraestrutura de saneamento suficiente para atender a toda população. Dessa forma, a disposição inadequada de esgotos domésticos para as praias se torna condição bastante comum nessas localidades (Cetesb, 2016). Esgotos domésticos, quando lançados diretamente ao mar, sem qualquer tipo de tratamento, carregam uma variedade de micro-organismos patogênicos que põem em risco a saúde do homem e a qualidade do ambiente (Who, 2003; Pinto et al., 2011).

Os corpos de água contaminados por esgotos domésticos, ao atingirem as águas das praias, podem expor os banhistas a microorganismos patogênicos, como vírus, bactérias, fungos, protozoários e ainda ovos de helmintos. Crianças, idosos ou pessoas com baixa resistência são as mais suscetíveis a infecções após o banho em águas contaminadas. Do ponto de vista de saúde pública, é importante considerar não apenas a possibilidade da transmissão de doenças de veiculação hídrica aos banhistas (gastroenterite, hepatite A, cólera, febre tifoide), mas também a ocorrência de outras doenças como conjuntivite, otite e doenças das vias respiratórias (Cetesb, 2016).

No Estado do Rio Grande do Norte, o monitoramento das águas é realizado pelo Instituto de Desenvolvimento Sustentável e Meio Ambiente do Estado do Rio Grande do Norte (IDEMA), Instituto de Gestão das Águas do Estado do Rio Grande do Norte (IGARN) e Empresa de Pesquisa Agropecuária do Estado do Rio Grande do Norte
(EMPARN), de acordo com a resolução $n^{\circ}$ 274/00 do Conselho Nacional do Meio Ambiente (CONAMA), embora algumas localidades turísticas ainda não sejam monitoradas, podendo causar situações indesejáveis aos banhistas, como é o caso do estuário da Reserva de Desenvolvimento Sustentável Estadual Ponta do Tubarão (RDSEPT), instituída pela Lei Estadual n ${ }^{\circ} 8.349 / 2003$, que fica localizada no litoral setentrional do estado do Rio Grande do Norte, abrangendo os municípios de Macau e Guamaré $\left(5^{\circ} 2\right.$ ' S e $5^{\circ} 16^{\prime}$ S; 36 $33^{\circ}$ ' W e $36^{\circ} 32^{\prime}$ W). Esta unidade de conservação ambiental apresenta uma diversidade de ecossistemas: porção marinha, caatinga, restinga, estuário, manguezais, dunas, falésias e está incluída entre as áreas prioritárias para a conservação da biodiversidade, sendo considerada de importância biológica muito alta (Dias, 2006), o que a torna um importante destino turístico regional. Entretanto, a ausência de planejamento e zoneamento ambiental resultou na ocupação desordenada da orla estuarina, agravada pela falta de saneamento básico, que favorece, dentre outros aspectos, o lançamento de efluentes domésticos em águas estuarinas, aliada à disposição inadequada de resíduos sólidos urbanos e à presença de animais circulantes em área estuarina, tornando a exposição a essas águas, por meio de atividades de contato primário, um risco iminente à saúde de seus usuários.

No tocante às águas estuarinas, a ausência de monitoramento ambiental em uma das principais unidades de conservação do Estado do Rio Grande do Norte, a Reserva de Desenvolvimento Sustentável Estadual Ponta do Tubarão (RDSEPT), justifica a necessidade de se conhecer os parâmetros microbiológicos, físico-químicos e os impactos ambientais ressaltados na Resolução Conama $n^{\circ}$ 274 de 29 de novembro de 2000, para que atividades potenciais de pesca artesanal e turística possam ser alavancadas como forma de desenvolvimento socioeconômico. Assim, a presente pesquisa objetivou conhecer os parâmetros microbiológicos, físico-químicos e os impactos ambientais do lançamento de efluentes domésticos 
e da disposição inadequada de resíduos sólidos urbanos no estuário da RDSEPT.

\section{Material e métodos}

Durante 10 semanas, no período de julho a outubro de 2016, foram colhidas em 5 pontos do estuário da Reserva de Desenvolvimento Sustentável Estadual Ponta do Tubarão (Figura 1), no município de Macau - Rio Grande do Norte, 50 amostras de $1.000 \mathrm{~mL}$ de água, em vidro de cor âmbar, esterilizado. A amostragem foi realizada em locais com lâmina d'água média de 1,0 metro, pois se caracteriza como a principal faixa de uso do estuário para a recreação. As amostras foram acondicionadas em bolsa isotérmica e transportadas para o Laboratório de Microbiologia Veterinária - LAMIV do Centro de Ciências Biológicas e da Saúde da Universidade Federal Rural do Semi-Árido, em Mossoró/RN para a realização das análises microbiológicas e físicoquímicas.
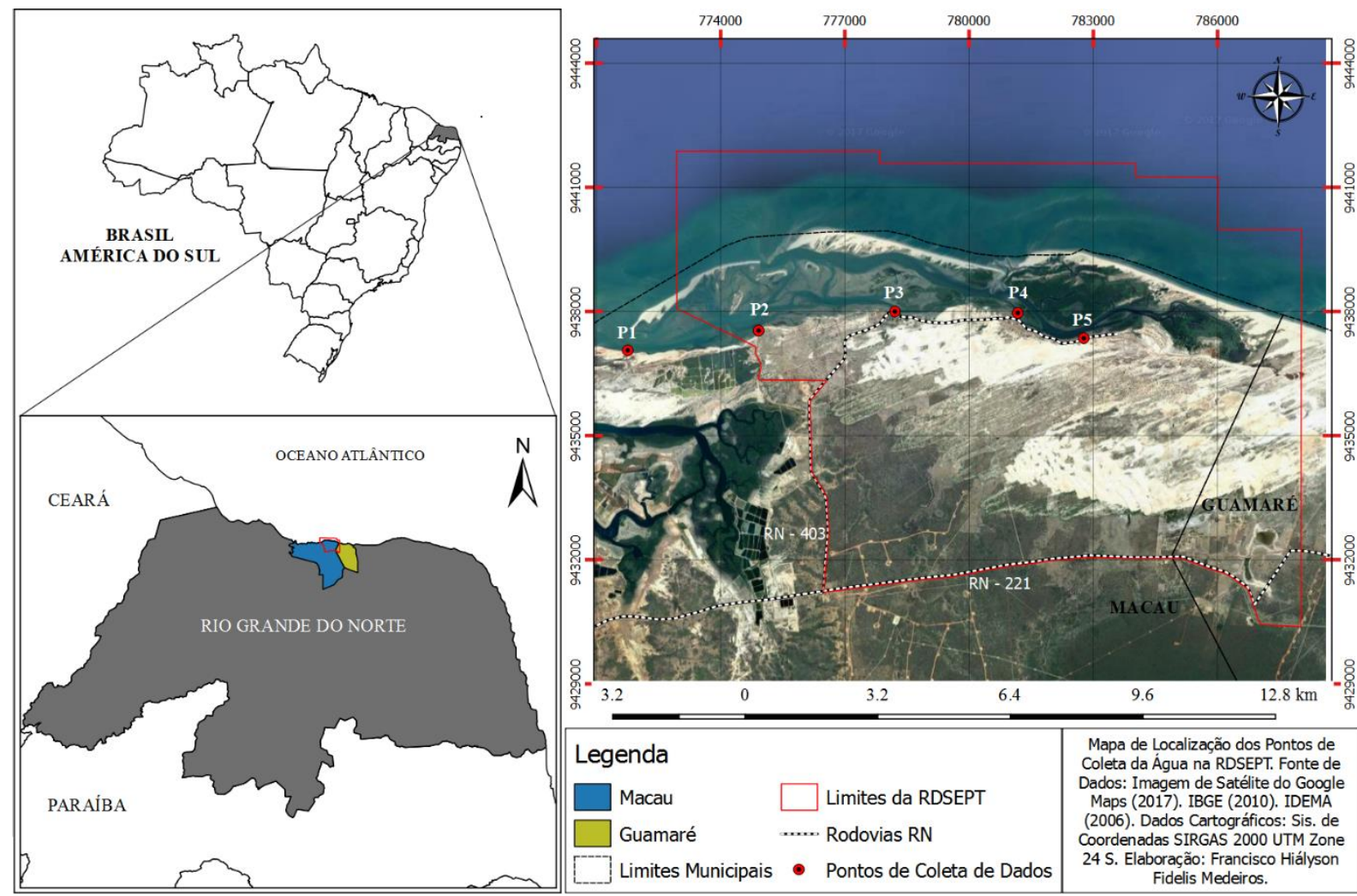

Figura 1. Mapa da área de estudo, indicando os pontos de coleta na Reserva de Desenvolvimento Sustentável Estadual Ponta do Tubarão. Coordenadas geográficas em Sirgas 2000 UTM zone 24: P1: $771760.90 \mathrm{~m} \mathrm{E}$ 9437058.33 m S; P2: 774924.05 m E - 9437535.72 m S; P3: 778224.71 m E - 9437997.39 m S; P4: 781170.95 m E - $9437965.21 \mathrm{~m} \mathrm{~S}$; P5: $782765.51 \mathrm{~m} \mathrm{E}$ - $9437353.83 \mathrm{~m} \mathrm{~S}$.

Para a determinação de coliformes totais, foi empregada a técnica dos tubos múltiplos, na qual se utilizou, inicialmente, três séries de 5 tubos contendo Caldo Lauril Sulfato de Sódio e tubos de Durham invertidos, adicionando-se, na primeira série, $10 \mathrm{~mL}$ de água estuarina, em caldo duplamente concentrado, seguida de duas séries de 5 tubos com concentração normal, adicionando-se 1 e $0,1 \mathrm{ml}$ da água, respectivamente. Após a incubação por $24-48$ horas a $37^{\circ} \mathrm{C}$, os tubos que apresentaram turvação e gás nos tubos de Durham foram considerados como positivos para a prova presuntiva para coliformes totais. Para o teste confirmativo para os coliformes totais, transferiramse alíquotas dos tubos positivos no Caldo Lauril Sulfato de Sódio, com auxílio de uma alça de platina para tubos contendo Caldo Bile Verde Brilhante Lactose a 2\%. (Caldo VB). A turvação desse meio e a produção de gás, após 24 a 48 horas de incubação a $45 \mathrm{oC}$, classificou os tubos como sendo positivos. Para a determinação do NMP de coliformes termotolerantes, os tubos considerados positivos no Caldo VB foram semeados em Caldo Escherichia coli (EC), também contendo tubos de Durham invertidos. Os tubos foram incubados em banhomaria a $45^{\circ} \mathrm{C}$, por um intervalo de 24 a 48 horas. 
Após a incubação, foram considerados positivos para a presença de coliformes termotolerantes, os tubos que apresentaram turvação e gás nos tubos de Durhan.

Para a determinação do NMP de Escherichia coli, os tubos considerados positivos no Caldo de Escherichia coli (EC), foram semeados em Caldo Triptona e incubados em banho-Maria a $450 \mathrm{C}$, por um intervalo de 24 a 48 horas. Os tubos foram considerados positivos após turvação e adição do reativo de Kovacs com formação de um anel vermelho da superfície do caldo Triptona. Em seguida, realizou-se o plaqueamento seletivo, a partir de cada tubo positivo no Caldo Triptona, em ágar Eosina Azul de Metileno (EMB), utilizando-se a técnica de estrias por esgotamento. As placas inoculadas foram invertidas e incubadas a $35^{\circ} \mathrm{C}$ por 24 horas em estufa. Decorrido o período de incubação, as colônias características de E. coli, colônias típicas negras e bordas claras ou colônias com brilho verde metálico, foram submetidas à série bioquímica: Indol, Vermelho de Metila, Voges Proskauer e Citrato (IMViC).

Para quantificação de Enterococcus sp. foi empregada a técnica tubos múltiplos, na qual utilizou-se uma série de 5 tubos com Caldo Azida Dextrose (CAD) duplamente concentrado, seguida de duas séries de 5 tubos com CAD em concentração normal, adicionando-se em cada série de 5 tubos, 1 e $0,1 \mathrm{ml}$ da água estuarina, respectivamente. Os tubos foram incubados a $35^{\circ} \mathrm{C}$ por 48 horas, e aqueles que apresentaram turvação tiveram seu conteúdo estriado em placas contendo o meio ágar m- Enterococcus $(\mathrm{pH} 7,5)$ e incubadas invertidamente a $35 \pm 2^{\circ} \mathrm{C}$ por 24 horas. O crescimento de colônias típicas vermelhas ou escuras com halo marrom determinava colônias suspeitas de Enterococcus sp. Em seguida, foram transferidas três colônias da cultura para tubos contendo Caldo Infusão Cérebro Coração (BHI) e incubados a $35 \pm 2^{\circ} \mathrm{C}$ por 24 horas para obtenção do inóculo. Posteriormente, foi realizado o teste de catalase, coloração de Gram, turvação em caldo $\mathrm{BHI}$ pH 9,6 incubados a $35^{\circ} \mathrm{C} / 48 \mathrm{~h}$, em caldo BHI a $45^{\circ} \mathrm{C} / 48 \mathrm{~h}$, em caldo $\mathrm{BHI}$ contendo $6,5 \%$ de $\mathrm{NaCl}$ a $35^{\circ} \mathrm{C} / 72 \mathrm{~h}$ e produção de colônias em ágar Bile Esculina a $35^{\circ} \mathrm{C} / 24 \mathrm{~h}$.

O NMP de coliformes totais, coliformes termotolerantes, Escherichia coli e Enterococcus sp. foi obtido através da combinação dos tubos positivos com as provas bioquímicas de acordo com a tabela de Hoskins.

Os aspectos físico-químicos como o $\mathrm{pH}$, a temperatura e salinidade foram verificados, em campo, através de medidor multiparâmetro com GPS (Modelo HI 9828) da marca HANNA instruments ${ }^{\circledR}$, e os dados pluviométricos foram obtidos junto ao site do Instituto Nacional de Meteorologia (INMET), por meio de planilha eletrônica.

Os impactos ambientais foram verificados através da ferramenta de controle check-list (Sánchez, 2013), por meio da qual foi gerada uma listagem descritiva das atividades e/ou ações e suas interfaces. As atividades/ações foram fotografadas e georreferenciadas com auxílio de câmera fotográfica NIKON p510 e GPS portátil (Garmin eTrex 30).

As amostras foram submetidas às análises microbiológicas com a finalidade de quantificar e identificar os micro-organismos indicadores de contaminação fecal e análise descritivas para posteriormente correlacionar os índices permitidos pela Resolução no 274 , de 29 de novembro de 2000 do CONAMA.

Os dados foram tabulados em planilha eletrônica. Para análise estatística, foi empregado o teste de Friedman com auxílio do programa R (R Core Team, 2016), considerando o nível de significância de $5 \%$ para análises microbiológicas e físico-químicas. As variáveis Coliformes Totais e Termotolerantes, Escherichia coli e Enterococcus sp., foram transformadas para log ((NMP/100mL) + 1). E ainda foi aplicada estatística descritiva para as observações dos impactos ambientais.

\section{Resultados e discussão}

Os dados relativos aos registros de $\mathrm{pH}$, salinidade e temperatura das amostras de água da orla estuarina coletadas da RDSEPT estão dispostos na Figura 2. Os parâmetros $\mathrm{pH}$, temperatura e salinidade não apresentaram diferenças estatísticas entre os pontos coletados. Os valores de $\mathrm{pH}$ variaram de 7,79 a 8,60, a temperatura, em ${ }^{\circ} \mathrm{C}$, variou de 23,48 a 31,43 e a salinidade em \%o variou de 36,40 a 40,95. Esses índices são considerados no padrão de acordo com a Resolução CONAMA n ${ }^{\circ}$ 357, de 17 de março de 2005 e permitem o crescimento de bactérias patogênicas e indicadoras de poluição ambiental, já que favorecem microclima estável aos organismos procariontes. Dados semelhantes foram encontrados por Monteiro (2013), quando identificou Enterococcus sp. em praias do litoral cearense e os valores detectados de $\mathrm{pH}$ nas águas do mar variaram de 7,60 a 8,40, temperatura em média de $27 \pm 1^{\circ} \mathrm{C}$ e salinidade na frequência de 36 a 39. Já Silva et al. (2008) encontraram variação de 7,0 a 8,0 quanto ao pH da água das praias no litoral 
do estado do Maranhão, quando estudavam sua contaminação por Enterococcus sp. E Rodríguez et al. (2015) verificaram a presença de Pseudomonas sp. e Enterococcus sp. em galerias pluviais e em águas marinhas receptoras na cidade de Fortaleza, Ceará, nas quais os valores de $\mathrm{pH}$ variaram entre 6,67 e 7,69, os de salinidade 20 e
40 e a temperatura entre $31^{\circ} \mathrm{C} \mathrm{e} 36^{\circ} \mathrm{C}$. Durante todo o período de coleta, realizada na Reserva de Desenvolvimento Sustentável Estadual Ponta do Tubarão, os valores pluviométricos foram $0,0 \mathrm{~mm}$ (INMET, 2016).
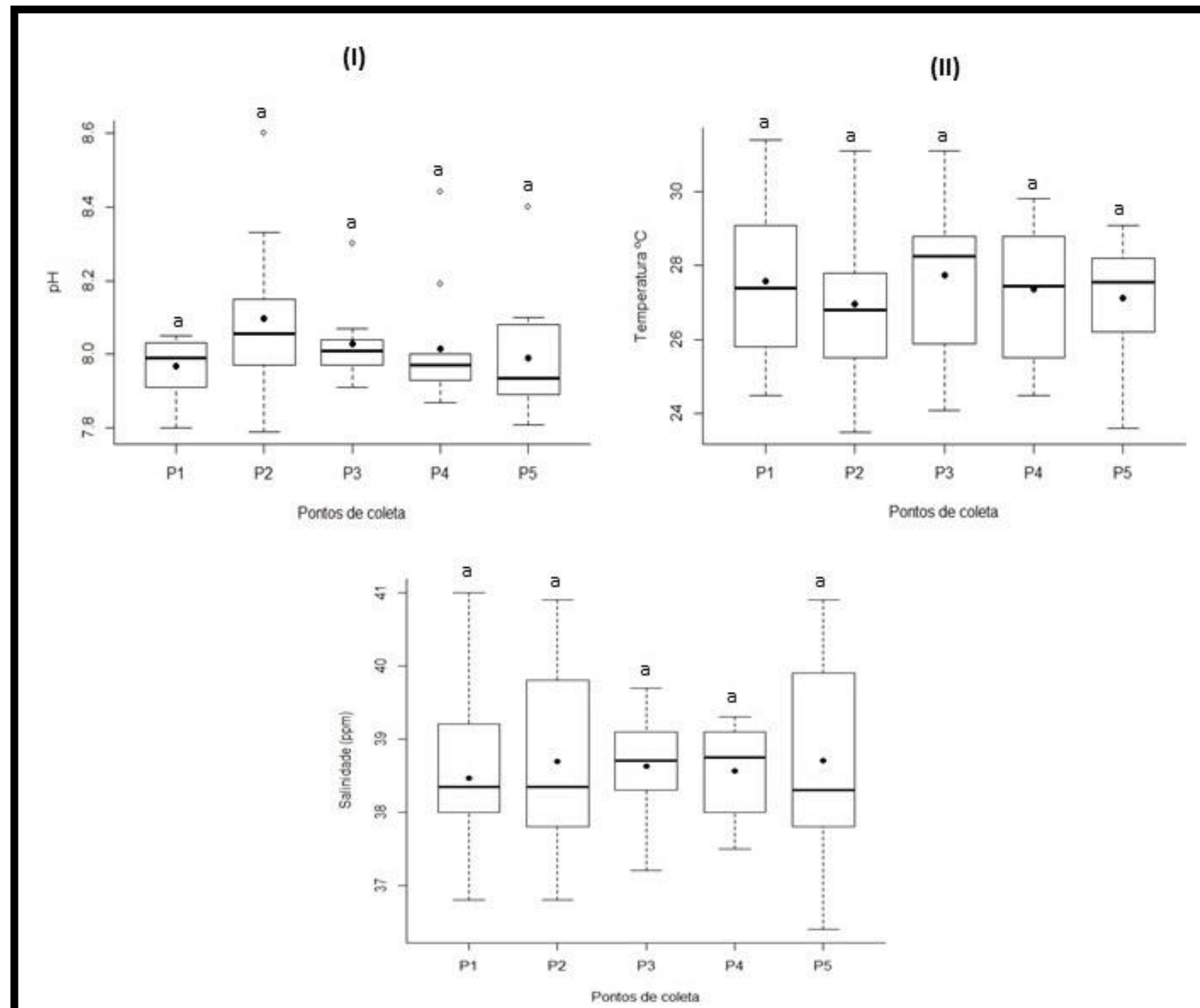

(III)

Figura 2. Boxplots das análises físico-químicas. (I) pH; (II) Temperatura $\left({ }^{\circ} \mathrm{C}\right)$; (III) Salinidade (ppm). Os pontos de coleta P1, P2, P3, P4 e P5 correspondem, respectivamente, ao acesso principal de água marinha no estuário, à comunidade de Chico Martins, à comunidade de Barreiras, à comunidade de Diogo Lopes e à comunidade de Sertãozinho, pertencentes à Reserva de Desenvolvimento Sustentável Estadual Ponta do Tubarão, localizada no município de Macau no Rio Grande do Norte. Na análise estatística foi empregado o teste de Friedman com auxílio do programa R (R Core Team, 2016), considerando o nível de significância de 5\%. Fonte: Dados da Pesquisa (2016).

Os dados referentes às análises microbiológicas das amostras de água da orla estuarina da RDSEPT foram dispostos na Figura 3. Durante as 10 coletas realizadas observou-se, no que se refere a Coliformes Totais (Cto), que existiu diferença estatística entre os pontos 3 e 4 em relação aos pontos 1 e $2(\mathrm{p}=0.003)$. O ponto 5 , no entanto, não apresentou diferenças estatísticas em relação aos demais pontos $(\mathrm{p}>0.05$ ) (Figura 3I). Para se avaliar a qualidade sanitária das águas, mais especificamente a qualidade microbiológica, muitos pesquisadores têm utilizado a colimetria - 
avaliação da contaminação da água por bactérias do grupo coliformes (Faria et al., 2001). Apesar de não determinar o risco da presença de vírus e, portanto, não garantir totalmente a qualidade da água, a avaliação da contaminação por coliformes ainda é bastante realizada em estudos de monitoramento ambiental. Esses dados foram referenciados de acordo com o caldo bile verde brilhante lactose $2 \%$ que apresentou 46 amostras (92\%), de um total de 50 amostras, com turvação e formação de gás, caracterizando presença de Cto. A quantificação de coliformes totais, expressa em log (10), nas amostras de águas, variou de 0,0 a 3,2 NMP/100mL no Ponto 1 ; de 0,0 a 3,4 no Ponto 2; de 0,9 a 3,4 no Ponto 3; de 1,0 a 3,4 no Ponto 4 e de 0,5 a 3,4 no Ponto 5. Esses resultados são justificados possivelmente pela presença de animais e dejetos lançados na orla de estuário. Oliveira et al. (2012), estudando a qualidade microbiológica do estuário do Rio Paciência/MA, observaram que as concentrações de coliformes totais e dos termotolerantes estiveram associadas à heterogeneidade espacial dos pontos amostrados e à influência de áreas urbanizadas, o que condiz com o que foi percebido nesta pesquisa. Nos pontos 3 e 4 do estuário da RDSEPT, equivalentes às comunidades de Barreiras e Diogo Lopes, respectivamente, onde a concentração urbana é bem maior que nos outros pontos de coleta.

A presença de coliformes termotolerantes indica contaminação de origem fecal indicando a possibilidade de detecção de micro-organismos enteropatogênicos (Sutiknowati, 2006). Assim, os agentes das infecções intestinais ou entéricas são, em geral, transmitidos ao homem através da veiculação por alimentos ou pela água contaminada. Referente aos Coliformes Termotolerantes (Cto), nota-se que existe diferença estatística entre os pontos 3 e 4 em relação aos pontos 1 e $2(\mathrm{p}=0.001)$. O ponto 5 , no entanto, não apresentou diferenças estatísticas em relação aos pontos 1, 2, 3 e 4 (p > 0.05) (Figura 3 -II). Esses dados foram referenciados de acordo com o caldo EC (Escherichia coli) que apresentou 41 amostras (82\%), de um total de 50 amostras com turvação com formação de gás, caracterizando presença de Cto. A quantificação de coliformes termotolerantes, expressa em log (10), nas amostras de águas variou de 0,0 a 1,3 NMP/100mL no Ponto 1 ; de 0,0 a 1,6 NMP/100mL no Ponto 2; de 0,4 a 3,2 NMP/100mL no Ponto 3; de 0,4 a 2,7 $\mathrm{NMP} / 100 \mathrm{~mL}$ no Ponto 4 e de 0,0 a 1,7 NMP/100mL no Ponto 5. Cardonha et al. (2004) verificaram índices de Cto elevados em três praias da cidade de Natal (RN), tendo como fonte principal e contínua de poluição a presença de tubos de esgoto ligados clandestinamente à galeria pluvial. Durante a realização das coletas do presente estudo, situações semelhantes foram observadas em Barreiras, Diogo Lopes e Sertãozinho, nas quais o lançamento de efluentes domésticos é contínuo na área de estuários destas três comunidades. Vieira et al. (2011), quando verificavam fontes de poluição de origem fecal nas praias de Fortaleza/CE, também encontraram valores de coliformes termotolerantes superiores a $\log 10$ 3,0 NMP/ 100 mL. Já Lourenço et al. (2006), analisando a água da praia das Barreiras, em Camocim no Ceará, encontraram valores de Cto muito menores: de 7 a 1100/100 mL (0,8 a 3,0 $\log 10 \mathrm{NMP} / 100 \mathrm{~mL}$ ), sendo essa praia considerada própria em todas as semanas de seus experimentos.

Em todos os pontos foi identificada a presença de Escherichia coli, cujo habitat primário é o trato gastrintestinal do homem e de animais, implicando que de alguma forma, resíduos orgânicos têm atingido o ambiente. Este é o microorganismo predominante entre os de origem fecal, cujo habitat exclusivo é o trato intestinal de animais homeotérmicos; onde seus percentuais equivalem a 98\% da flora intestinal (APHA, 2005). Conforme Vieira et al. (2001), quando se quer constatar que a contaminação ocorreu por meio de esgotos, um dos patógenos mais importantes para ser pesquisado é a E. coli. Esta bactéria tem como um dos fatores limitantes a salinidade, que influencia na velocidade de sua multiplicação. Além disto, outros fatores podem também importar na sua sobrevivência, tais como temperatura, radiação solar e competição com outros microorganismos.

Castro et al. (2006), trabalhando com um microcosmo experimental com água marinha e E. coli, ressaltaram o efeito da radiação solar associado à temperatura sobre essa bactéria. A cepa de E. coli com a qual os autores trabalharam havia sido isolada de uma galeria pluvial em Fortaleza. A quantificação de E. coli (EC) não apresentou diferença estatística entre os Pontos 1,2,3,4 e 5 ( p > 0.05) (Figura 3-III). Os dados foram referenciados de acordo com o Caldo Triptona Soja que apresentou 20 amostras (40\%), de um total de 50, com turvação, caracterizando presença de E.coli , os quais foram confirmados por meio da série bioquímica IMVIC. A quantificação de E. coli, expressa em log (10), nas amostras de águas variou de 0,0 a $1,0 \mathrm{NMP} / 100 \mathrm{~mL}$ no Ponto 1 ; de 0,0 a 1,5 NMP/100mL no Ponto 2; de 0,0 a 1,3 NMP/100mL 
no Ponto 3; de 0,0 a $1,4 \mathrm{NMP} / 100 \mathrm{~mL}$ no Ponto 4 e de 0,0 a $1,1 \mathrm{NMP} / 100 \mathrm{~mL}$ no Ponto 5. Os valores baixos de E. coli, possivelmente, podem ser justificados uma vez que o ambiente marinho possui alta osmolaridade e limitação de nutrientes sendo, desta forma, um ambiente hostil para este tipo de micro-organismo (Gourmelon et al.,1997). $\mathrm{O} \mathrm{pH}$ da água do mar situa-se normalmente entre 7,5 e 8,5, sendo influenciado pela temperatura, pressão, atividades fotossintéticas e respiratórias dos micro-organismos. Um $\mathrm{pH}$ ácido, na faixa de 5,0, favorece a sobrevivência de E. coli, já a faixa em torno de 8,0 exerce um efeito deletério na sobrevivência da bactéria (Rosen e Belkin, 2001), o que pode ter influenciado significativamente nos dados referenciados para E. coli quantificados nesta pesquisa. Lourenço et al. (2006), analisando a água da praia das Barreiras, em Camocim, no Ceará, encontraram valores de E. coli em torno de 2 a 170 NMP/100 mL (0,3 a 2,2 $\log 10$ NMP/100 mL), considerando-a própria para utilização dos banhistas.

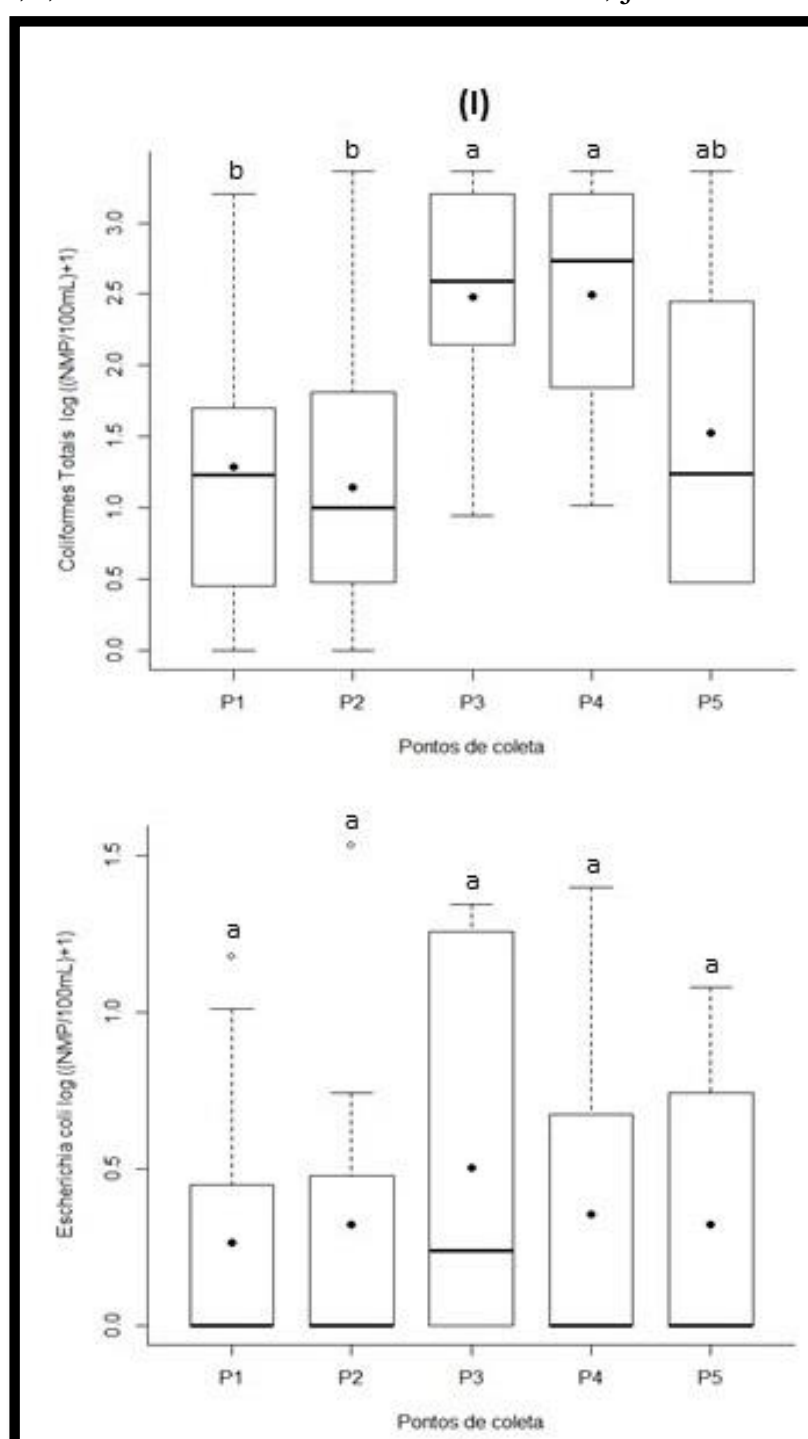

(III)
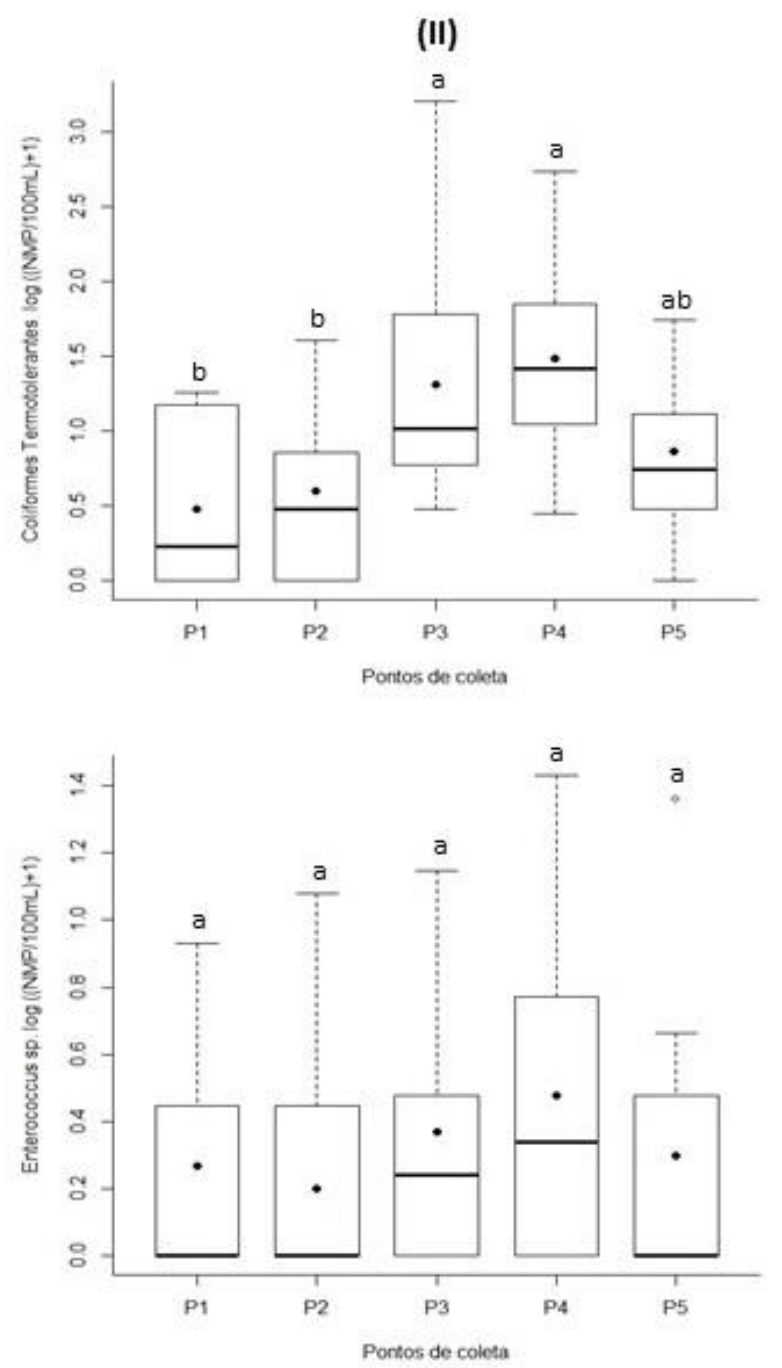

(IV)

Figura 3. Boxplots das análises microbiológicas. (I) Coliformes Totais; (II) Coliformes Termotolerantes; (III) Escherichia coli e (IV) Enterococcus sp., expressos em $\log 10((\mathrm{NMP} / 100 \mathrm{~mL})+1)$. Os pontos de coleta P1, P2, P3, P4 e P5 correspondem, respectivamente, ao acesso principal de água marinha no estuário, a comunidade de Chico Martins, a comunidade de Barreiras, a comunidade de Diogo Lopes e a comunidade de Sertãozinho, pertencentes à Reserva de Desenvolvimento Sustentável Estadual Ponta do Tubarão, localizada no município de Macau no Rio Grande do Norte. Na análise estatística foi empregado o teste de Friedman com auxílio do programa R (R Core Team, 2016), considerando o nível de significância de 5\%. Fonte: Dados da Pesquisa (2016). 
Segundo Mcfeters et al. (1974), através de vários estudos, Enterococcus sp. foi eleito como indicador de excelência para a classificação da qualidade das águas de origem marinha, por possuir inúmeras vantagens tais como: não crescer no ambiente e apresentar um amplo tempo de sobrevivência na água marinha, sendo mais resistente quando comparado aos coliformes termotolerantes e à $\mathrm{E}$ coli. Por ser indicador de contaminação de origem fecal, sua presença na água evidencia inadequação nas condições sanitárias da água do estuário, o que pode causar doenças nos usuários da praia tais como gastroenterites, se ingerida, dentre outras (Duarte, 2011). A quantificação de Enterococcus sp. (ET) não apresentou diferença estatística entre os Pontos 1,2,3,4 e 5 ( $\mathrm{p}>0.05$ ) (Figura 3-IV). Os dados foram referenciados de acordo com o ágar m-Enterococcus, que apresentou 21 amostras (42\%), de um total de 50 com turvação, caracterizando presença de ET, os quais foram confirmados por meio da série bioquímica. A quantificação de Enterococcus sp., expressa em $\log (10)$, nas amostras de águas, variou de 0,0 a 0,9 NMP/ $100 \mathrm{~mL}$ no Ponto 1 ; de 0,0 a 1,0 NMP/100mL no Ponto 2; de 0,0 a 1,1 NMP/100mL no Ponto 3; de 0,0 a 1,2 NMP/100mL no Ponto 4 e de 0,0 a 1,4 NMP/100mL no Ponto 5.

Estes são importantes indicadores ambientais de contaminação hídrica por bactérias de contaminação fecal. As concentrações de Enterococcus sp. encontradas nas análises das amostras de água da orla estuarina da RDSEPT podem ter sido influenciadas pela interação de fatores ambientais tais como as marés, a radiação solar e as chuvas, entre outros (Enns et al., 2012). As contagens de bactérias obtidas nos pontos de coleta com valores de $\mathrm{pH}$ de 7,60 mínimo a 8,40 máximo, respectivamente, ratificam o critério de que bactérias pertencentes ao gênero Enterococcus sp. são capazes de crescer a valores de $\mathrm{pH}$ próximos a 9,6 (CETESB, 2012). Os resultados ratificam a informação de que bactérias pertencentes ao gênero Enterococcus sp. podem sobreviver por mais tempo em águas marinhas, devido à sua capacidade de tolerar altas concentrações de sais (Harwood et al., 2000). Silva et al. (2008), quando pesquisava a qualidade da água da praia do Calhau, em São Luís no Maranhão, percebeu que as amostras de água apresentaram concentrações elevadas de Enterococcus sp., as quais variavam de 170 a $1600 \mathrm{NMP} / 100 \mathrm{~mL}(2,2$ a $3,2 \log 10 \mathrm{NMP} / 100 \mathrm{~mL}$ ), caracterizando-as impróprias para banho. Neste mesmo sentido, Dalfior (2005), quando analisava amostras de água marinha na Praia da Curva da Jurema, em Vitória/ES, encontrou resultados semelhantes aos do presente estudo.

A balneabilidade dos balneários, segundo os critérios estabelecidos pela legislação vigente (Resolução $\mathrm{N}^{\circ} 274$ do CONAMA, 2000), é determinada pelo índice de coliformes fecais (CF), Escherichia coli ou Enterococcus sp. encontrados em suas águas. As águas são classificadas como Excelente, Muito Boa, Satisfatória e Imprópria, sendo as três primeiras categorias agrupadas numa única classificação, como sendo Própria. De acordo com essa Resolução, um local será considerado Impróprio para a prática de recreação quando em $80 \%$ ou mais, de um conjunto de amostras de águas, coletadas no mesmo local, durante cinco semanas consecutivas, a densidade de Enterococcus sp. for superior a 400 NMP $100 \mathrm{ml}-1 \quad(2,6 \log 10$ NMP/100 mL), a 2500 NMP $100 \mathrm{ml} \mathrm{-1} \mathrm{(3,4} \log 10$ $\mathrm{NMP} / 100 \mathrm{~mL})$ de coliformes fecais (termotolerantes), ou, ainda, a $2000 \mathrm{NMP} 100 \mathrm{ml}$ $-1(3,3 \log 10 \mathrm{NMP} / 100 \mathrm{~mL})$ de Escherichia coli em uma única amostra. Neste trabalho, de acordo com os valores de Enterococcus sp. e Escherichia coli encontrados, os locais de coleta foram considerados "Próprios" na categoria "excelente" pela legislação (Brasil, 2000) em 100\% das coletas. Já os valores referentes aos Coliformes Termotolerantes foram considerados "Próprios" em $90 \%$ das coletas (Figura 4). 


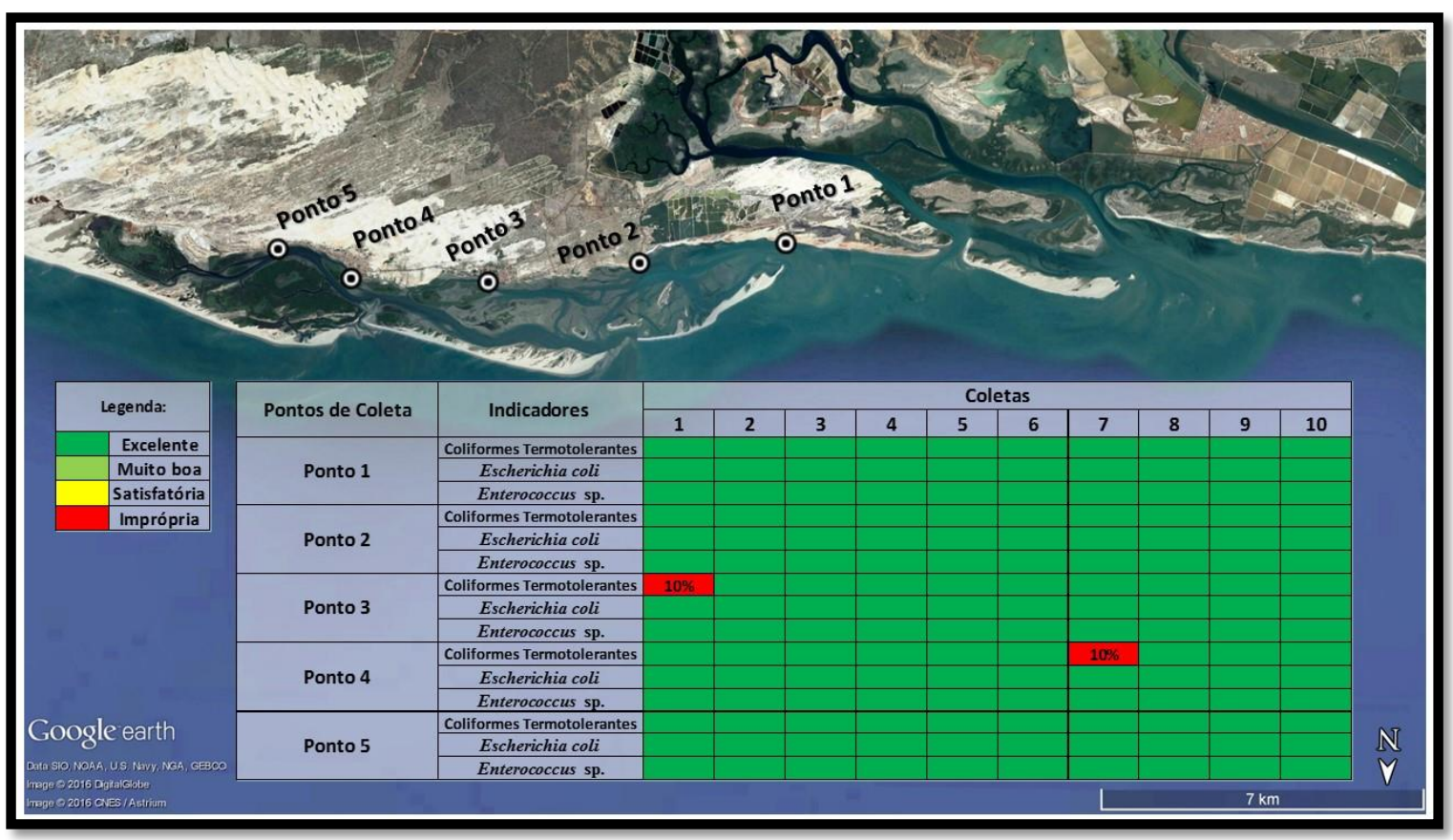

Figura 4 - Balneabilidade, em porcentagem, da Orla do Estuário da Reserva de Desenvolvimento Sustentável Estadual Ponta do Tubarão ao longo das 10 coletas realizadas. Fonte: Modificado de Google Earth, 2016.

Por outro lado, o $\S 4^{\circ}$ do Artigo $2^{\circ}$ da Resolução $n^{\circ}$ 274/2000 do CONAMA afirma que as águas serão consideradas impróprias quando, no trecho avaliado, for verificada a presença de resíduos ou despejos, sólidos ou líquidos, inclusive esgotos sanitários, óleos, graxas e outras substâncias, capazes de oferecer riscos à saúde ou tornar desagradável a recreação. Assim, a ausência de saneamento básico na RDSEPT oportuniza que a população encontre meios inadequados para destinação de seus efluentes domésticos (Figura 3 - I). A maioria das residências têm seus efluentes sanitários destinados para sumidouros e as águas cinzas são destinadas para locais a céu aberto ou para via pública, levados para o estuário por meio das canaletas artesanais construídas para essa finalidade. Foram identificados 205 pontos de lançamento de efluentes na orla do estuário. Destes, 3 pontos estão na comunidade de Sertãozinho, 133 em Diogo Lopes e 69 em Barreiras. Os impactos ambientais provenientes dessas ações podem causar a modificação do equilíbrio hidrológico do estuário da RDSEPT, alterações no habitat da flora e fauna aquática, a produção de odores desagradáveis, além do comprometimento do solo, a proliferação de vetores transmissores de doenças e a contaminação das águas subterrâneas, uma vez que grande parte das comunidades está sobre dunas, o que facilita a infiltração destes efluentes o que pode aumentar os riscos de contaminação e comprometimento da saúde pública local.

A presença de animais domésticos por toda a orla do estuário foi constante. Em todas as coletas foram observadas diversas espécies de animais (galináceos, caprinos, asininos, bovinos, suínos, caninos e felinos) defecando e se alimentando de resíduos sólidos urbanos dispostos de forma inadequada na orla estuarina (Figura 5 - II). A presença destes animais em área de estuário pode ocasionar a contaminação do solo e da água por meio das fezes, a atração de micro-organismos, que podem causar doenças, poluição visual, contaminação de organismos aquáticos, especialmente os filtradores, o acumulo ou excesso de matéria orgânica na água, a diminuição do oxigênio dissolvido na água, odores desagradáveis e riscos aos banhistas.

A disposição inadequada de resíduos sólidos urbanos (Figura 5 - III) constitui uma permanente ameaça à saúde pública e ao meio ambiente, limitando as potencialidades 
econômicas locais. Mediante contato de pessoas e animais domésticos com o lixo, nas áreas de depósito, pode ocorrer a disseminação de enfermidades. Também o vento pode ser um veículo de transporte de elementos patogênicos e materiais perigosos. Depósitos de RSU foram encontrados por quase toda a
RDSEPT, em especial nas comunidades Barreiras e Diogo Lopes por serem as mais populosas e com características urbanas. $\mathrm{Na}$ orla estuarina foram encontrados 7 pontos de disposição inadequada de resíduos sólidos urbanos, sendo 1 em Sertãozinho, 4 em Diogo Lopes e 3 em Barreiras.

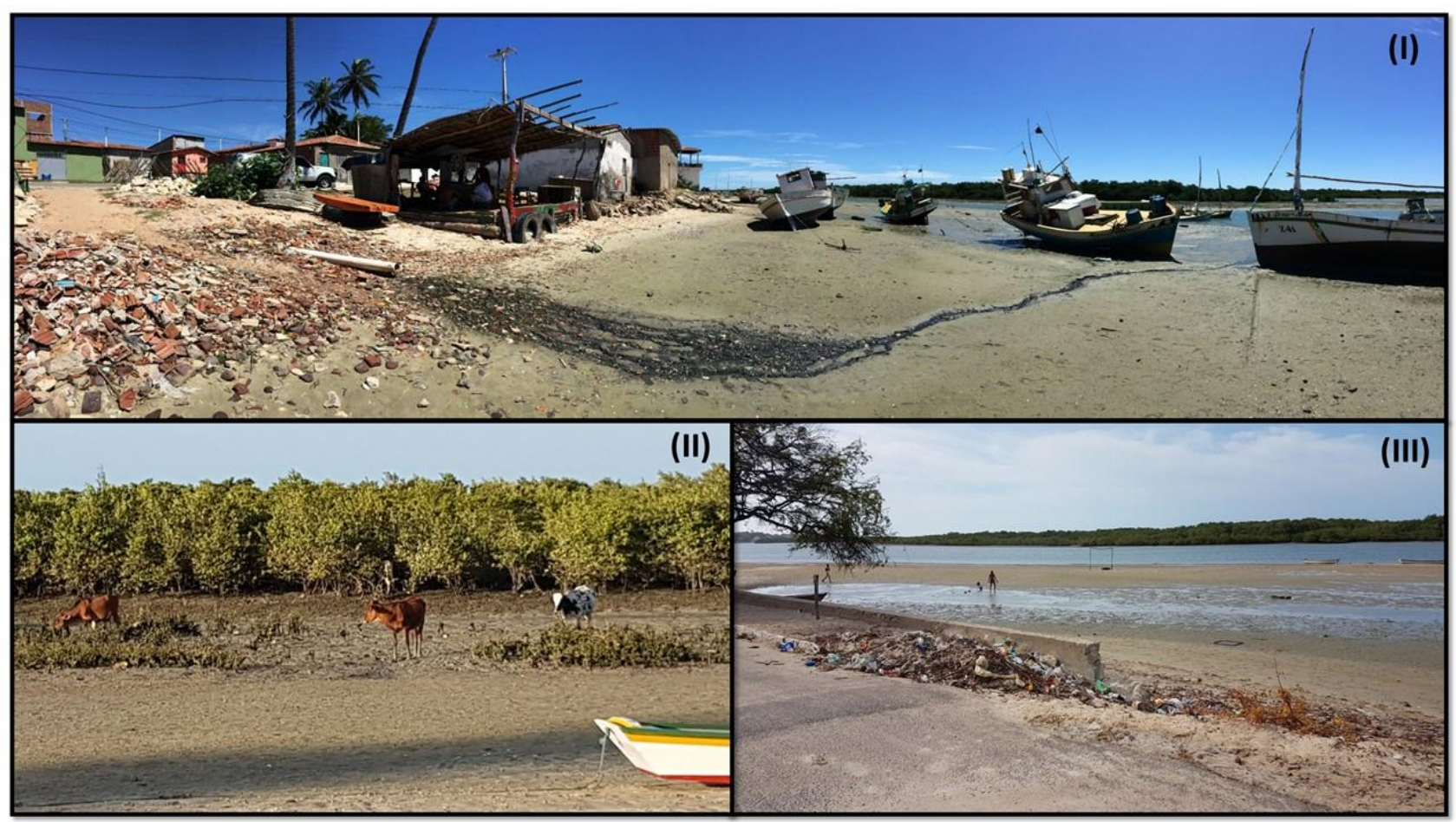

Figura 5 - I - Lançamento de efluentes domésticos na orla estuarina; II - Animais domésticos pastando em área de estuário; III - Disposição inadequada de resíduos sólidos urbanos na orla do estuário.

Fonte: Dados da Pesquisa (2016).

\section{Conclusão}

Quanto aos coliformes totais e termotolerantes, foram encontrados valores dentro dos limites estabelecidos na legislação em $90 \%$ das amostras, e $100 \%$ das amostras de Escherichia coli e Enterococcus sp. foram consideradas próprias na categoria excelente.

No que se refere ao $\mathrm{pH}$, salinidade e temperatura, os índices encontrados estão dentro dos limites permitidos pela Resolução CONAMA no 357, de 17 de março de 2005 e possibilitam o crescimento de bactérias patogênicas e indicadoras de poluição ambiental, já que favorecem microclima estável aos organismos procariontes.

Por outro lado, por meio do checklist, foram georreferenciados 205 pontos de lançamento de efluentes domésticos e 7 áreas de disposição inadequada de resíduos sólidos urbanos em área de estuário, esses dados classificam a água do estuário como inapropriada para o banho.

Conclui-se que as águas da orla estuarina da RDSEPT apresentam os índices físico-químicos de acordo com os padrões estabelecidos e estão contaminadas com bactérias de origem fecal, com concentrações inferiores aos limites permitidos, no entanto, em vários pontos, a orla apresenta a disposição inadequada de resíduos sólidos urbanos, lançamento de efluentes domésticos e/ou sanitários, considerando o trecho pesquisado inapropriado pela Resolução ${ }^{\circ}$ 274/2000 do CONAMA 


\section{Referências}

APHA, 2005. Standard methods for the examination of water and wastewater American Public Health Association, Washington.

BRASIL. Conselho Nacional de Meio Ambiente, 2000. Resolução $\mathrm{n}^{\circ} 274$, de 29 de novembro.

Cardonha, A.M., Vieira, R.H.S.F., Rodrigues, D.P., Macrae, A., Peirano, G., Teophilo, G.N.D., 2004. Fecal pollution in water from storm sewers and adjacente seashores in Natal, Rio Grande do Norte, Brazil. International Microbiology 7, 213-218.

Carr, M.R., Wang, T.I., McLean, T.I., Flood, C.J., Ellender, R.D., 2010. Salmonella rarely detected in Mississippi coastal waters and sediment. Journal of Applied Microbiology 109, 2191-2199.

Castro, H. M. P., Vieira, R. H. S. F., FontenelesFilho, A. A., Hofer, E., Albuquerque, W. F., 2006. Efeito da radiação solar da salinidade sobre o crescimento de Escherichia coli. Arquivos de Ciência do Mar 39, 28-33.

CETESB. Companhia Ambiental do Estado de São Paulo, 2012. Enterococos - Determinação pela técnica de membrana filtrante: método de ensaio. Norma técnica L5.212. São Paulo.

CETESB. Companhia Ambiental do Estado de São Paulo, 2016. Qualidade das praias litorâneas no Estado de São Paulo - 2015. São Paulo.

Dalfior, J. S., 2005. Avaliação da eficiência do grupo coliforme fecal como indicador de balneabilidade de praias quando comparado com Enterococos: Estudo de caso da praia da Curva da Jurema. Monografia (Graduação em Oceanografia) Centro de Ciências Humanas e Naturais. Vitória, Universidade Federal do Espirito Santo.

Dias, T. L. P., Salles, R., 2006. Diagnóstico da pesca artesanal e proposta de plano de ordenamento da pesca na reserva de desenvolvimento sustentável Ponta do Tubarão (Macau Guamaré/RN). Idema, Natal.

Duarte, P. B., 2011. Microrganismos indicadores de poluição fecal em Recursos Hídricos. Monografia (Especialização em
Microbiologia). Belo Horizonte, Universidade Federal de Minas Gerais.

Enns, A.A., Vogel, L.J. Abdelzaher, A.M., SoloGabriele, H.M., Plano, L.R.W., Gidley, M.L., Phillips, M.C., Klaus, J.S., Piggot, A.M., Feng, Z., Reniers, A.J.H., Haus, B.K., Elmir, S.M., Zhang, Y., Jimenez, N.H., Abdel-Mottaleb, N., Schoor, M.E., Brown, A., Khan, S.Q., Dameron, A.S., Salazar, N.C., Fleming, L.E., 2012. Spatial and temporal variation in indicator microbe sampling is influential in beach management decisions. Water Research 46, 2237-2246.

Faria, B.M., Farjalla, V.F., Esteves, F.A., 2001. Aquatic microbial ecology in Brazil. Serie Oecologia Brasiliensis 9, 197-216.

Gourmelon, M., Touati, D., Pommepuy, M., Cormier, M., 1997. Survival of Escherichia coli exposed to visible light in sea water: analysis in seawater analysis of rpoSdependent effects. Canadian Journal of Microbiology 43, 10361043.

Harwood, V.J., Whitlook, J., Withington, V., 2000. Classification of antibiotic resistance patterns of indicator bacteria by discriminant analysis: Use in predicting the source of fecal contamination in subtropical waters. Applied and Environmental Microbiology 66, 36983704.

INMET. Instituto Nacional de Meteorologia., 2016. Banco de Dados Climatológicos. Disponível em:

http://www.inmet.gov.br/portal/index.php?r=b dmep/bdm ep.>. Acesso em: 31 de julho de 2016

Lourenço, E.M.L., Vieira, G.H.F., Festivo, M.L., Rodrigues, D.P., Vieira, R.H.S.F., 2006. Balneabilidade das praias do Odus e das Barreiras (Camocim, Ceará). Boletim Técnico. Cientifico 6, 19-32.

Mcfeters, G. A., Bissonnette, G. K., HjezeskI, J. J., Thomsom, C. A., Stuart, D. G., 1974. Comparative survival of indicator bacteria and enteric pathogens in well water. Applied. Microbiology 27, 823-829.

Monteiro, D. T. L., 2013. Comparação da qualidade

Ferreira Filho, J. M., Feijó, F. M. C., Carvalho, R. G. Bergamo, G. C., Oliveira, P. V. C., Matos, T. M., Santos, C. S. 
bacteriológica da água marinha e da areia seca e molhada de duas praias do litoral leste do Ceará. Dissertação de Mestrado em Ciências Marinhas Tropicais. Fortaleza, Universidade Federal do Ceará.

Oliveira, D.R.P., Castro, A.C.L., Nascimento, A.R., Soares, L.S., Porto, H.L.R. 2012. Avaliação do grau de contaminação microbiológica do estuário do Rio Paciência, Estado do Maranhão. Arquivos de Ciência do Mar 45, 56-61;

Oliveira, J.F., Novaes, J. L. C., Segundo, A. L. N. M., PERETTI, D., 2016. Caracterização da pesca e percepção de pescadores artesanais em uma Reserva de Desenvolvimento Sustentável no Nordeste brasileiro. Natureza Online 14, 48-54.

Pinto, A.B., Pereira, C.R., Oliveira, A.J.C., 2012. Density of Enterococcus $\mathrm{sp}$ in recreational waters and beach sand in São Vicente-SP, Brazil and its relationship to abiotic parameters. O Mundo da Saúde 36, 587-593.

R Core Team. R., 2016. Language and environment for statistical computing. Vienna: $R$ Foundation for Statistical Computing. Disponivel: URL https://www.R-project.org/. Acesso: 02 de Setembro de 2016.

Rodriguez, M.T.T., Oliveira, A. E. Q., Sousa, O.V., Vieira, R. H. S. F., 2015. Presença de Pseudomonas e Enterococcus em galerias pluviais em aguas marinhas receptoras na cidade de Fortaleza, Ceara. Arquivos de Ciências do Mar 48, 49-56.
Rozen, Y., Belkin, S. 2001. Survival of enteric bacteria in seawater. FEMS Microbiology Reviews, 725, 1-17.

Sánchez, L. E., 2013. Avaliação de impacto ambiental, $2^{a}$ ed. Oficina de textos. São Paulo

Silva, V.C., Nascimento, A. R., Mourão, A. P. C., Neto, S. V. C., Costa, F. N., 2008. Contaminação por Enterococcus da água das praias do município de São Luís, Estado do Maranhão. Acta Science. Technology 30, 187192.

Sutiknowati, L.I., 2006. Bacteriological study of the marine water in the coastal of the North Sulawesi province, Indonesia. Makara Sains 10, 76-82.

Vieira, R. H. S. F., Silva, P. R. F. G., Sousa, O. V., Leitugeur, L. G. O., 2001. Balneabilidade das águas da praia do Futuro. Arquivos de Ciências do Mar 34, 39-42.

Vieira, R.H.S.F., Menezes, F.G.R., Costa, R.A., Marins, R.V., Abreu, L.M., Fonteles-Filho, A.A., Sousa, O.V., 2011. Galerías pluviais como fonte de poluição de origem fecal para as praias de Fortaleza-Ceará. Arquivos Ciências do Mar 44, 5-12.

WHO. World Health Organization, 2003. Guidelines for Safe Recreational Water environments, v. 1, Genebra. 